\title{
Digital Literacy of Employees in Production Process - Analyse of Production Stability and Productivity in INDUSTRY 4.0 Concept
}

\author{
Felicita Chromjakova ${ }^{1, *}$
}

1 Department of Industrial Engineering and Information Systems, Faculty of Management and Economics, Tomas Bata University in Zlin, Czech Republic

\begin{abstract}
Important part of the higher productivity and effectiveness in today's industrial enterprises confronted with growing automation and digitization of production processes is strong connected with the ability of employees to be prepare communicate with newest digitized production technologies. Skills and abilities of employees influence radical the productivity, performance, value added of production flows. Presented paper analyse important parameters of digital literacy of employees in production processes and confronts the results with the core requirements on continuously process performance and improvement. Results achieved by presented analyse are useful for development of digitized process management schemas, prediction of effective value stream in production process.
\end{abstract}

\section{Keywords:}

\section{Introduction}

Industrial Enterprises was open in last years an interesting point - teamwork between employee and digitized technology. Valuable perspective of the applicability of digitized technologies as cloud computing, big data systems, 3D visualisations and projections bring in the world of process management new impulses for job standardisation, workplace organization and production process planning and management improvements. Concept INDUSTRY 4.0 opens the next industrial revolution and open new horizons of productive and innovative thinking. Firstly, there is necessary to identify the computational intelligence $(\mathrm{Cl})$, this involve the knowledge of computer algorithm to capture hidden knowledge from data and to use them for training "intelligent machine" to make complex decisions without human intervention (Chromjakova,2017). As simulation is becoming more prevalent from design and planning to manufacturing and operations, material processing can also benefit from computer generating knowledge through soft computing. Secondly the vision of smart shop floor is based on the INDUSTRY 4.0 that denotes technologies and concepts to cyber-physical production systems. In smart shop floors, cyber-physical system monitors physical processes, creates a virtual copy of the physical world, and makes decentralized decisions. Cyber-physical production systems is the digitized and with relevant software support automatized technology, it allows virtual world to store data, process data, communication, cooperation with each other in real time. Every physical entity in the smart shop floor is regarded as an autonomous intelligent logical unit that performs operations guided by distributed control functions. Computing power and optimisation approaches are embedded into each logical unit to make decisions to agilely respond to frequent occurrence of unexpected disturbances at the shop floor (Tang, Zheng, Zhang, Sang, 2018).

With the recent introduction of ambitious industrial concepts as INDUSTRY 4.0, a massive focus has been placed on the development of and efficient robotic 
workplaces connected with human digital literacy. Amongst all the operations robotic systems can take care of, handling remains a preferred choice due to a combination of factors including its oftenrepetitive nature and low skill requirement. In industrial companies, innovation and production process improvement is considered a relevant aspect of success and long-term survival. Industrial companies should be able recognize that innovation contributes from digitized production systems create the competitive advantage in a more competitive, challenging and changing labour market (Palazzeschi, Bucci, Di Fabio, 2018).

Core goal of the research presented in this paper is the identification and verification of scientific hypothesis, connected with the content of most important pillars of digital literacy by production employees.

\section{Theoretical background of production digital literacy}

The fourth industrial revolution is characterised by the increased use of digital tools, allowing for the virtual representation of a real production environment at different levels, from the entire production plant to a single machine or a specific process or operation. In this framework, digital factory technologies, based on the employment of digital modelling and simulation tools, can be used for short term analysis and validation of production control strategies or for medium term production planning or production system design/redesign. To configure and verify correct layout of the upgraded manufacturing cell with the aim to increase its performance in terms of resource utilisation and throughput time, 3D motion simulation and discrete event simulation are jointly employed for the modelling and simulation of different cell settings for proper layout configuration, safe motion planning and resource utilisation improvement (Caggiano, Teti, 2018).

INDUSTRY 4.0 is an epoch-making revolution which brought the manufacturing market much faster changes and severer competitions. As an important part of the manufacturing system, facility layout has direct impact on business benefit, at the same time, despite the intelligent factory, intelligent production has its own characteristics. However, there is one point on which industry that have basically formed a consensus: it is not true that
INDUSTRY 4.0 does not need human beings, on the contrary, human initiative plays and unabated role in the development of INDUSTRY 4.0. Based on the digitized production system and the traditional optimization model, the mathematical models built the best solution for combining safety, sustainability, high efficiency, and low cost (Li,Tan, 2018).

Augmented reality is a key technology for the development of smart manufacturing. One of the main advantages of augmented reality is that it can help workers to accomplish several tasks, making it possible the shift from mass production to mass customization. However, it is still not clear how these promises can be fulfilled in an industrial scenario. In particular, the question about which display solutions fit better the industrial constraints remains open (Uva, Gattullo, Manghisi, Spagnulo, Cascella, Florentino, 2018).

Digitized technologies with artificial intelligence and automated supermarkets run by collaborative robots (cobots) working without human supervision have sparked off new debates: what will be the impact of extreme automation, turbocharged by the Internet of Things, artificial intelligence and the INDUSTRY 4.0, on Big Data and omics implementation science? The Internet of Things builds on broadband wireless internet connectivity, miniaturized sensors embedded in animate and inanimate objects ranging from the house cat to the milk carton in smart fridge, and artificial intelligence and cobots making sense of big data collected by sensors INDUSTRY 4.0 is a high-tech strategy for manufacturing automation that employs the Internet of Things, thus creating the Smart Factory. Extreme automation until "everything is connected to everything else" poses, however, vulnerabilities that have been little considered to date. First, highly integrated systems are vulnerable to systemic risks such as total network collapse in the event of failure of one of its parts, for example, by hacking or internet viruses that can fully invade integrated systems. Second, extreme connectivity creates new social and political power structures. If left unchecked, they might lead to authoritarian governance by one person in total control of network power, directly or through her/his connected surrogates (Ozdemir, Hekim, 2018).

With the advent of INDUSTRY 4.0 maintenance strategy faces new demands to avoid the hysteresis of the conventional passive maintenance mode 
and the non-feasibility of the periodic preventive maintenance mode. In view of the inherent polymorphism of manufacturing systems and with the objective of maximizing benefits, there is important to proper a novel cost-oriented predictive maintenance based on mission reliability state for manufacturing system (He,Han,Gu,Chen, 2018).

\section{Analyse and research of key production process digital literacy parameters}

Today's industrial enterprises are confronted by implementation of INDUSTRY 4.0 concept with basic problem - stabilised manufacturing and supporting processes. In the world of traditional industrial firms, there is another revolution. It is characterized by the transition from sophisticated factories to smart factories, complex manufacturing processes and systems supporting digital and virtual process and production technologies. Computer-driven digital management processes monitor physical transaction processes, creating the original computer copy of the 3D virtual reality process, which is the basis for designing and managing production systems. Physical objects thus become digital objects transformed in the form of digital data into horizontal and vertical information networks and in the form of virtually shared data that serve as a basis for real-time added value creation. The result is more flexible processes, optimal real-time production schedule, effective multivariate production.

Key interests of scientific research were derivatives from the individual interview, realized during 20162017 in 300 industrial companies in Czech and Slovak Republic. Interest groups were production directors, masters, supervisor, team leaders, machine labor. Formulation of core research hypothesis for the identification of production process digital literacy by employment:

H1 Interoperability - cyber-physical systems link each other's human activities to compact, intelligent processes that communicate with each other on a digital basis

H2 Virtualization - by sharing virtual copies of production systems, online digital sensors create data that can be used in virtual 3D planning and control simulation models, while providing data for $3 \mathrm{D}$ product prints in real-world production

H3 Decentralization of process management - the ability of cyber-physical systems to make real-time decision making in the form of a digital manager

H4 Real-time data availability of the digital manager - the definition of services claimed by manufacturing processes and systems provides full electronic support for on-line production process management

H5 Modularity - Flexible adaptation of smart plants and smart manufacturing technologies to change production requirements, effective change management with support of digital manager

The questionnaire survey also highlighted the fact that the automation and digitization of production and supporting production processes is also important in setting up a process of digitization of production processes, where the knowledge and experience of employees of selected workplaces can be used with a high efficiency to continually increase the performance of production processes. Here is a demonstrably high assumption that the production technology is eligible for the subsequent digitization of processes in connection with the digital setting of the worker's position. It also has the potential to create new qualifications for workers in digitized production.

Next will be tested the following through digitized technologies managed tasks (results achieved by individual interview in 300 industrial companies, the results in the table 1 are summarisation of important answers and further scientific deductions).

Research results can be summarized follows:

$\underline{\mathrm{H} 1}$

Under "human activities" we understand all activities connected with preparation of production plan - realization of production order by workplace - expedition of order to customer with strong cooperation with computer aided production system. "Human" should know the rules and standards of communication with computers and digitized machines. An industrial company has clearly identified processes that it wants to integrate within Industry 4.0 in according to the interoperability of employees integrated in the digitized production technologies. The verification of this hypothesis has confirmed that most industrial companies are uniquely focused on the identification of key horizontal processes, oriented directly to the design and management of production processes, and other supporting processes on the vertical line only marginally. The key processes digital literacy abilities and competencies necessary to implement the Industry 4.0 concept were marked:

$\checkmark$ Integration of production planning and management - $26 \%$ of companies

$\checkmark$ Digitization and automation of manufacturing processes - 18\% 
Tab. 1: Core tasks realized by employment in digitized technologies (source: author).

\begin{tabular}{ll}
$\begin{array}{l}\text { Specification of production } \\
\text { order }\end{array}$ & $\begin{array}{l}\text { Setting up and digitizing of identification codes for product parts and relevant types of } \\
\text { production operations } \\
\text { Creating digital bindings of the "product - manufacturing process" } \\
\text { Providing comprehensive digital inputs and outputs }\end{array}$ \\
$\begin{array}{l}\text { Production portfolio } \\
\text { management by production } \\
\text { cell }\end{array}$ & $\begin{array}{l}\text { Identification, setting up and standardization of the collaborative platform for the digitally } \\
\text { controlled manufacturing process } \\
\text { Flexible simulation of the production process } \\
\text { Database of availability and performance parameters of production technologies }\end{array}$ \\
\hline $\begin{array}{l}\text { Production planning and } \\
\text { scheduling }\end{array}$ & $\begin{array}{l}\text { Setting up and standardizing the platform and procedures for digital decision making } \\
\text { Personalization / Setting up the e-carrier of digital links } \\
\text { Flexible job organization } \\
\text { Install and manage cloud storage of production data }\end{array}$ \\
$\begin{array}{l}\text { Multi-level, digitally-organized production scheduling in real time } \\
\text { Organization and administration of data analytics in real time } \\
\text { Creating online error identification and fault elimination }\end{array}$ \\
$\begin{array}{l}\text { Production process } \\
\text { realization }\end{array}$ \\
$\begin{array}{l}\text { Online Workplace Performance Monitoring Scheme } \\
\text { Optimizing material and information flows } \\
\text { Digital management of production processes }\end{array}$ \\
$\begin{array}{l}\text { Setting up a digital protocol for testing the quality of the manufactured product, the } \\
\text { production process being carried out } \\
\text { Creation of digitally controlled process improvement systems }\end{array}$ \\
\hline
\end{tabular}

of companies

$\checkmark$ Quality management online in manufacturing processes - $14 \%$ of companies

$\checkmark$ Flexible real-time production organization - $12 \%$ of companies

$\checkmark$ Adequate personification of production processes and on-line organized communication and management of production processes - $11 \%$ of companies

$\checkmark$ Optimal setting of supply chains linked to manufacturing processes - $11 \%$ of companies

$\checkmark$ Setting up maintenance systems and on-line monitoring of machines and equipment - $10 \%$ of companies

$\checkmark$ On-line reception and production organization based on customer order specification - $10 \%$ of companies

$\mathrm{H} 2$

An industrial company has virtualized production and supporting processes, enabling to the staff simply electronically managed designing, planning and organization of production tasks on flexible production basis. An absolute prerequisite for implementing the Industry 4.0 concept is the company's ability to have stabilized key manufacturing processes. Forty percent of companies in the automotive industry spoke out of this hypothesis, for the engineering industry $82 \%$ of the companies confirmed the validity of the hypothesis, 92\% were declared by subcontractors for automotive companies and 56\% were for the other industry category. In summary, the automotive sector has the greatest need to stabilize key processes.

In according to the identification of important virtualized knowledges and skills there were identified following:

$\checkmark$ mechatronics digital literacy - primarily, production technology focuses on minimizing downtime and cost savings in the presence of flexible, modular and casting tools that are able to quickly change ideally while running technology and quickly adapt to new manufacturing settings. This also means that these process elements will claim minimal interference within a defined industrial engineering when integrating into existing production processes. We use the "Plug-and-Play Paradigma" principle for this installation. Because the sub-production modules are heavily dependent on each other and vary greatly, there must be a mechanism to automatically identify, identify and evaluate the typology of the production system. $\checkmark$ provision of modular procurement infrastructure in conjunction with the possibility of mutually combining selected production modules universally and with minimum configuration costs, there must be adequate procurement infrastructure within a given system architecture that takes the appropriate functionality in procurement processes and management of procurement of production modules. These include energy procurement, data routing and comprehensive security management (security means the safety of used and transferred production dates between workplaces, suppliers and customers). The procurement infrastructure itself must be modular in order to have the required flexibility of production facilities and not just the source of process conflicts 
$\checkmark$ sklil with designing of individualized mass production - Production technology is able to operate economically even with lower production batches. The architecture of the digital process scheme must assume a solution that makes it possible to uniquely identify manufactured products and then optimally link them in the production process. The solution must enable the production modules to individually structure and process the assigned production parameters. At the same time, it is necessary to maximize product and varied varieties - the processes integrated in the production module are assembled so that they can be realized through specific parameters in the widest possible variety $\checkmark$ internal and external network connectivity procedures possibilities and their service ability - the existence of a fast IT connection allowing transparent viewing of ongoing production processes, identification of error messages, subsequent activation of functions oriented primarily to the elimination of errors, thanks to these functionalities can be optimized in real time. The intersection information point must take the integration function and all relevant information and setting parameters directly from the manufacturing device, which then logically configures the standardized schema. At the same time, this intersection declares the inter continence of the production facilities, their parameters and functionalities. The architecture of the manufacturing system assumes the flexible integration of IT system for planning, control and optimization of production facilities through the modular setting of parameters and system elements. Newly developed IT systems must allow for a relatively quick and cheap integration of intersections and consequently a seamless modular functionality of all production facilities integrated in the production technology.

$\checkmark$ the goal of system architecture is the economic production of individual products under the conditions of mass production. The manufactured product is the starting point for the concept of manufacturing processes. Complexity and product variability define the number and layout of production modules as part of the production process.

$\checkmark$ the product specification is implemented with a view to product digitization (Product-ID), which allows direct connection to digitization of production processes and active control of production processes. In this context, the following specifications are included:

- Electromechanical specification - a mechanism for loading and describing a digital product

- Information and technical specifications - creation of digital product model

$\checkmark$ Each production module has a specific manufacturing, assembly, test or test process. Depending on the needs of the complex manufacturing process, it is possible to set individual parameters exactly. Depending on each product claiming an individually set manufacturing process, the individual manufacturing modules must be mutually compatible, relatively adaptable and cost-effective in terms of optimal interconnection.

$\underline{\mathrm{H} 3}$

The goals for decentralisation of process model were verified through the qualitative and quantitative research as follows:

$\checkmark$ create a comprehensive digital process map and digital management

$\checkmark$ clear and functional coordination of the production plan according to flexible production rules in conjunction with available production capacities and supporting production processes (production planning, logistics, quality, maintenance)

$\checkmark$ defined on-line prioritization of operations and tasks in connection with optimal sequential planning and implementation of "just in sequence optimization" manufacturing orders

$\checkmark$ marked physical objects (technologies, machinery, tools, and tools) have their item in a digital manager who schedules them for production operations and controls according to their assigned ID

$\checkmark$ cooperative scheduling and organization of production in the triangle "customer - producer - supplier" works optimally through the web interface, this interface actively and reliably utilizes the created interactive environment and data warehouse

$\checkmark$ an adequate process model is set to optimize the planning process, organization and production management by using large data warehouse and cloud computing to ensure customer satisfaction in real time (delivery of production order by given time schedule)

$\checkmark$ determined on-line optimal combination of supplier deliveries following on-line order / order specification from the customer, including current logistics delivery costs

$\checkmark$ continuously improving customer relationship and enhancing customer intelligence through programmable customer service centres with the intention of better programming of production capacities and their more efficient use in real time

H4

Real data time availability is based on the successful implementation of digitized technologies in the production process environment. The definition can be considered as key: "E-production is an Internet application in manufacturing. E-production is not just automation of production ("digital production") but an effective link between automation and Internet technologies (Hwaiyu, 2004). The concept of slim production in the link to agile production and constraint theory understands the implementation of e-production as a transformation of mass production into a group of flexible and efficient manufacturing processes. The goal of lean manufacturing is to produce only what the customer requires and at the same time minimal production costs. Restriction theory requires optimizing material and information flows while minimizing bottlenecks in production. Both of these models are entirely dependent on the ability to adequately anticipate future production 
requirements and the setting of an optimal "pull" system, which assumes:

$\checkmark$ implementation of the Manufacturing Execution Software (MES) in order to coordinate production scheduling and scheduling, set process quality and manufactured products, deploy SCADA / HMI systems for data capture and analysis in functional machine-to-person interface with respect to productivity of production technologies, management of maintenance and warehouse management

$\checkmark$ adequate interconnection of the MES system with the ERP system (Enterprise Resource Planning), which brings to the system the organization and control of the flow of the source requirements in the production process, which subsequently interconnects with the parameters of the supply and customer chain in the form of on-line Internet communication.

Implementing this infrastructure for building e-production brings many positive effects: 25$60 \%$ material stock reduction, $30-45 \%$ reduction in cycle times, 17-55\% WIP inventory reduction, 35$55 \%$ reduction in administrative preparation of the planning process and production control Hwaiyu, 2004). The indisputable fact of e-production is computer-aided production planning and organization (CAD, CAM, CAPP), especially if we work with a huge amount of production data and we strive to meet flexible requirements according to the daily forecast. As can be seen, linking data management, virtual reality and interfacing between simulation and customer demand is a prerequisite for this phase.

$\underline{\mathrm{H} 5}$

Modularity - flexibility of production system is strong determined through the relevant parameters, oriented on the modularity - flexibility mapping:

$\checkmark$ On-line frequency of planning and re-planning of production requirements (shorter product life cycles and correspondingly desirable reduction of production lead times)

$\checkmark$ the time-consuming process of digital planning and scheduling (the need for a faster delivery to the customer)

$\checkmark$ Quality and reliability of scheduling and scheduling of production processes (reducing the cost of supporting production processes)

$\checkmark$ Flexibility of planning in the digital environment by better allocation and setting of competences for process and activity process holders (emphasis is placed on optimizing alternative production costs and utilization of technologically and digitally managed production capacities)

$\checkmark$ the complexity of the scheduling and scheduling process (essential condition is the optimal on-line communication in the chain "customer - production - supplier"

For digital planning purposes, it is appropriate to have a built-in digitized infrastructure that determines the downstream effects of digital production technologies.

\section{Proposal of digital literacy model for production process}

This general model can be used to set external as well as internal digitized processes. Based on the above general model, the above-mentioned general model of scheduling and scheduling of production can be specified as follows (see Figure 1).

Horizontal integration focuses on manufacturing technology, machinery and equipment scheduling, human capacity scheduling, material flows, and on-going automation of workplaces, capable of working on-line and under the management of digital technologies. The result of planning is a complete process map of the digitized process in connection with technical, technological and human resources. Horizontal integration allows the elimination of isolated workshop activities while maintaining a complex manufacturing process by concentrating all the activities of the manufacturing process into one compact unit that is directly linked to the resulting vertical integration module. Each process map element has an accurate digitized label and description that allows digitized technologies to be flexible in planning based on on-line orders for a given production system.

Vertical integration provides the transfer of work instructions and the flow of information from the simplest digital sensor to the workshop - to the corporate internet, cloud and other available technologies to support the digitization of production processes. It is good if these technologies are linked to MES, MRP, SAP. The main purpose of vertical integration is the elimination of excess data and the support of efficient online controlled information flows for digitally controlled production processes.

\section{Conclusions}

A very important trend is the area of digital literacy of production employs is the digital interconnection of ERP systems and PPS systems via MES systems (Trentesaux, 2009). With this integration, complex manufacturing processes can be optimally digitized, based on well-defined analysis, organization, management and production data management. This integration provides the basis for further digitization of manufacturing processes, followed by 
Digital literacy of employees in production processes

\begin{tabular}{|c|c|c|c|c|}
\hline $\begin{array}{l}\text { Production } \\
\text { planning }\end{array}$ & $\begin{array}{l}\text { Parameters } \\
\text { identification }\end{array}$ & $\begin{array}{l}\text { Layout } \\
\text { schedule }\end{array}$ & $\begin{array}{l}\text { Resources } \\
\text { schedule }\end{array}$ & $\begin{array}{l}\text { Process } \\
\text { designing }\end{array}$ \\
\hline $\begin{array}{l}\text { CAD } \\
\text { CAM } \\
\text { CAPP } \\
\text { simulation } \\
\text { infrastructure }\end{array}$ & $\begin{array}{l}\text { product ID } \\
\text { production ID } \\
\text { 3D production flow } \\
\text { 3D database }\end{array}$ & $\begin{array}{l}\text { layout proposal } \\
\text { capacity plan } \\
\text { process map }\end{array}$ & $\begin{array}{l}\text { production flow } \\
\text { workplace } \\
\text { date inventory } \\
\text { ergonomics } \\
\text { interface }\end{array}$ & $\begin{array}{l}\text { CAE, CAM } \\
\text { digital } \\
\text { standards } \\
\text { dates security }\end{array}$ \\
\hline
\end{tabular}

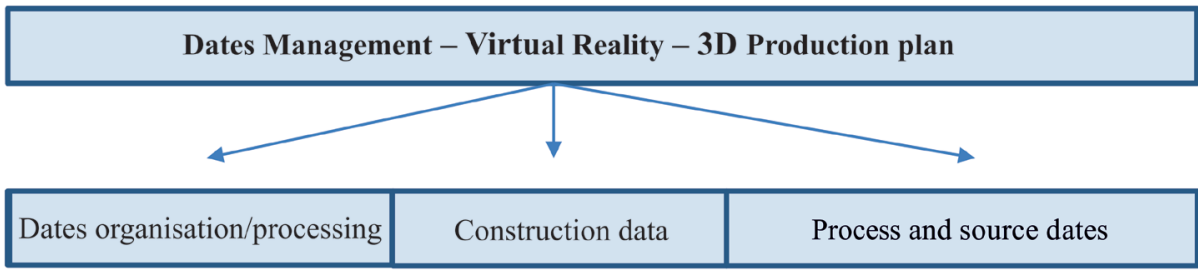

\begin{tabular}{|c|c|c|}
\hline construction data & preparation and data transfer & $\begin{array}{l}\text { compact database } \\
\text { limit of MRP }\end{array}$ \\
\hline production data & & limit of MRP \\
\hline workplace layout & flexible layout & lines balancing \\
\hline logistics & inventories request & workflow database \\
\hline machine data & on-line data monitoring & data basis \\
\hline vailability & on-line data & on-line monitoring \\
\hline $\begin{array}{l}\text { of labour } \\
\text { material flow }\end{array}$ & standardisation of flows & process data \\
\hline pperation plan & IP storage service & IP process driver \\
\hline
\end{tabular}

Fig. 1: Digital literacy of employees in production process (source: author).

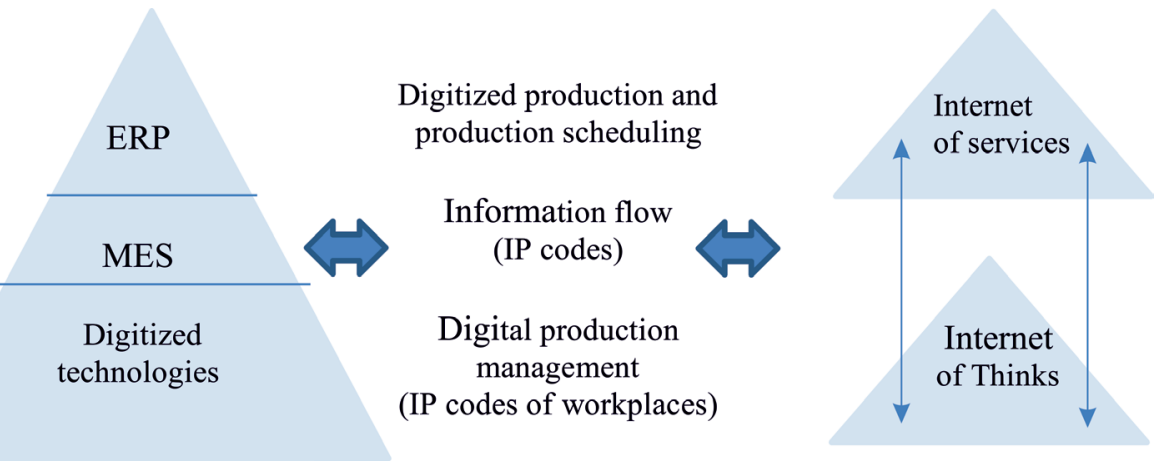

Fig. 2: Model of digital literacy by production employees (source: author).

the reduction of manual operations and processes throughout the production-administrative production chain.

One of the key trends is that companies must pay more attention to the accuracy and timeliness of data for product development and their subsequent production (Hou, 2017). If individual product components come from multiple manufacturers, digital technology and digitally managed production equipment must communicate effectively with one another. Here we talk about so-called digital networking technologies that claim different types of digital standards, and then new data transfer technologies among many industrial companies. Object Intelligence will be a completely new parameter, which we are starting to 
monitor very closely now, having a crucial impact on waste reduction, elimination of downtime, failure of machines and equipment. Just the tracking of sensors for each machine, digital technology or workplace delivers cloud-based on-line decisions to further run the production processes in real-time. Finally, we can formulate the definition of digital literacy as follows: digital literacy is the ability to use information and communication technologies to find, evaluate, create, and communicate information, requiring both cognitive and technical skills. The employee Is able to use diverse technologies appropriately and effectively to retrieve information, interpret results, and judge the quality of that information; next to understands the relationship between technology, life-long learning, personal privacy, and stewardship of information a uses these skills and the appropriate technology to communicate and collaborate with peers, colleagues, family, and on occasion, the general public.

This paper is result of RVO project realised by UTB - FAME: Development of complexly methodology of process planning, management and organisation by implementation and utilisation of INDUSTRY 4.0 concept in SMEs.

\section{References and Notes}

[1] Atan,Z., Ahmadi,T., Stegehuis,C., Kok,T., Adan,l.: Assembleto-order systems. A review. European Journal of Operational Research, Volume 261, Issue 3, pp. 866-879, 2017, ISSN 0377-2217

[2] Caggiano,A., Teti,R.: Digital factory technologies for robotic automation and enhanced manufacturing cell design. Cogent Engineering, Volume 5, Issue 1, 2018, ISSN 2331-1916

[3] He,Y., Han,X., Gu,C., Chen,Z.: Cost-oriented predictive maintenance based on mission reliability state for cyber manufacturing systems. Advances in Mechanical Engineering, Volume 10, Issue 1, 2018, ISSN 1687-8140

[4] Hirsch-Kreinsen,H.: Wandel von Produktionsarbeit - Industrie 4.0. Soziologisches Arbeitspapier Nr. 38/2014, Technische Universität Dortmund, ISSN 1612-5355

[3] Hou,L, Zhao,S.H., Li,X., Chatzimisios,P., Zheng,K.: Design and implementation of application programming interface for Internet of things cloud. International Journal of Network Management, Volume 27, Issue 3, 2017, ISSN 1055-7148

[6] Chromjakova,F.: Production Process Stability - Core Assumption of Industry 4.0 concept. 5th International Conference on Manufacturing, Optimization, Industrial and Material Engineering, Book Series: IOP Conference Series-Material
Science and Engineering, Volume 215, UNSP 012024, 2017

[4] Li,J., Tan,X., Li,JC.: Research on Dynamic Facility Layout Problem of Manufacturing Unit Considering Human. Mathematical Problems in Engineering, 2018, ISSN 1563-5147

[5] Ozdemir,V., Hekim,N.: Birth of Industry 5.0: Making Sense of Big Data with Artificial Intelligence. OMICS-A Journal of Integrative Biology, Volume 22, Issue 1, pp. 65-76, 2018, ISSN 1557-8100

[6] Palazzeschi,L., Bucci,O., Di Fabio,A.: Re-thinking Inovation in Organizations in the Industry 4.0 Scenario: New Challenges in a Primary Prevention Perspective. Frontiers In Psychology, Volume 9, 2018, ISSN 1664-1078

[7] Tang,D., Zheng,K., Zhang,H., Zhang,Z., Sang,Z., Zhang,T., Esponosa-Oviedo,J., Vargas-Solar,G.: Using autonomous intelligence to build a smart shop floor. International Journal of Advanced Manufacturing Technology. Volume 94, Issue 5-8, pp. 1597-1606, 2018, ISSN 0268-3768

[8] Trentesaux,D.: Distributed control of production systems. Engineering Applications of Artificial Intelligence, Volume 22, Issue 7, pp. 971-978, 2009, ISSN 0952-1976

[7] Uva,E., Gattullo,M., Manghisi,V., Spagnulo,D., Cascella,G., Fiorentino,M.: Evaluating the effectiveness of spatial augmented reality in smart manufacturing: a solution for manual working stations. International Journal of Advanced Manufacturing Technology, Volume 94, Issue 1-4, pp. 509521, 2018, ISSN1433-3015 